\title{
Flipped Classroom Teaching in Organic Chemistry in the Context of CLIL
}

\author{
Jesús Fernández Arteaga \\ University of Huelva
}

\author{
Patricia Remón Ruiz \\ University of Huelva
}

\author{
José Antonio González Delgado \\ University of Huelva
}

\author{
David Guzmán Ríos \\ University of Huelva
}

\begin{abstract}
This paper proposes an experience that involves the methodological model of the flipped classroom with the introduction of foreign language teaching, to promote the acquisition of transversal and linguistic skills in three subjects of the Degree in Chemistry at the University of Huelva (Spain). This proposal includes the implementation of this methodology in different didactic units of each one of the subjects. The method is developed in 4 different phases, starting with the programming of the experience; elaboration of the teaching material for its development, based on the autonomous work of the students; to the classroom work and resolution of doubts that take place in the classroom. The implementation of this teachinglearning experience has been globally successful.
\end{abstract}

Keywords: flipped classroom teaching, CLIL, organic chemistry, transversal skills

\section{INTRODUCTION}

One of the most significant and current objectives within university teaching is the promotion and improvement of teaching in a foreign language (DLEX). This objective has two purposes: the learning of a second language together with the specific contents of each degree, in order to achieve a higher degree of internationalization of the future university graduate, with a view to his or her personal and professional projection. In this way, teaching in a non-native language can promote the acquisition of transversal skills by students at the same time as basic skills, mainly by improving their linguistic competence. In addition, from the institutional point of view, the commitment to Content and Language Integrated Learning (CLIL) can promote an increase in the competitiveness of university teaching.

Furthermore, university education must promote the training of active, self-confident, curious, enterprising, and innovative people, who are capable of assuming as their own the value of balance between effort and reward. The education system must facilitate both learning different things and teaching in a different way, in order to satisfy students, who have been changing with society. Cognitive skills, although 
essential, are not enough; it is necessary to acquire from an early age transversal skills, such as critical thinking, creativity or the ability to communicate, and key attitudes such as individual confidence, enthusiasm, perseverance and acceptance of change.

To date, the classic teaching methodology, which we can consider having been applied for the most part and which has been the most traditional and widespread in the university environment, is the "master class". This can be defined as: "a teaching time entirely or mainly occupied by the continuous exposition of a lecturer. Students may have the opportunity to ask questions or participate in a small discussion but, in general, they do nothing but listen and take notes" (Angelo 1990, Isaza-Restrepo 2005, Sanchez 2013). The use and/or abuse of this type of teaching methodology has produced a problem of student attitude in the classroom: the student is in classes but his/her attention is not on the teacher's explanations since everything is focused on his/her speech and the material is generally displayed in the form of a PowerPoint presentation. This also contributes to an increase in absenteeism as the school year progresses, as well as a general lack of motivation. It is therefore important to promote a work method that encourages students and allows them to meet the objectives of acquiring skills in each subject of a degree program.

The new teaching method known as "flipped classroom" can be presented as the most appropriate for the implementation of a teaching-learning method that combines the two aforementioned concepts: foreign language teaching and autonomous student development. This pedagogical model was implemented by Bergmann and Sams (2012), it transfers the work of certain learning processes space temporarily outside the classroom and uses class time, together with the teacher's experience in order to facilitate and enhance other processes of knowledge acquisition and practice within the classroom. This methodology provides a comprehensive approach that combines direct teaching with constructivist methods, increasing students' engagement and involvement with the course content and improving their conceptual understanding.

Specifically, in this teaching strategy (flipped classroom), students work independently on tasks previously prepared for this purpose by the teacher (Jordan et al., 2014), which improves student learning through the exchange of teacher-student roles (Jiménez, 2013), since the student starts the study of the subject outside the classroom and deepens it in a face-to-face session in the classroom with the discussion of other students and the support of the teacher, directly affecting the way in which students learn and assimilate content.

Escalera et al. (2008) highlight some advantages and disadvantages of this methodology. The most remarkable are some of them such as: the easy availability for the student of the necessary information in order to complete the knowledge of the subject, previously selected by the teacher; the possibility to define a level of knowledge; the transmission of experiences and scientific enthusiasm regarding the subject of the lesson; or the fact that it is one of the few feasible ones for a high number of students. Furthermore, significantly, according to Sousa (1995), the knowledge retained after $24 \mathrm{~h}$ in a student is 5\% for master lectures, $50 \%$ for group discussions, and $75 \%$ for practical experiences (Sosa-Pérez, 2014). Therefore, a master lecture requires a great investment of time outside the classroom, in order for the student to assimilate knowledge.

\section{OBJECTIVES}

Based on the aforementioned, the main objectives of this educational research work are based on the methodological incorporation of a teaching strategy based on "the flipped classroom" in some of the didactic units of a set of subjects belonging to different semesters of the same undergraduate curriculum. More specifically, the study has been implemented in three subjects (Table 1) of the curriculum of the Degree in Chemistry at the University of Huelva, all of them taught in English as the common channel of communication. The incorporation of this methodology will potentially encourage the acquisition of numerous transversal skills such as critical reasoning, the ability to manage data and the creation of information/knowledge, the ability to organize and plan, the knowledge of a foreign language, etc. Significantly, the development of this methodology could motivate the promotion and improvement of teaching in a foreign language (DLEX) for the students of the Degree in Chemistry at the University of Huelva. 
TABLE 1

SUBJECTS INVOLVED IN THE EXPERIENCE

\begin{tabular}{|c|c|c|c|c|}
\hline Subject ${ }^{(a)}$ & Year & Semester & Type & $\begin{array}{l}\text { Number of } \\
\text { students (b) }\end{array}$ \\
\hline Organic Chemistry & $2^{\circ}$ & 2 & Mandatory & 73 \\
\hline Structural Elucidation of Organic Compounds & $3^{\circ}$ & 1 & Mandatory & 56 \\
\hline Organic Chemistry Laboratory & $3^{\circ}$ & 2 & Mandatory & 48 \\
\hline
\end{tabular}

(a) All belonging to the curriculum of the Degree in Chemistry of the University of Huelva.

(b) Average number of students in each subject over the three years of the experience.

\section{DESCRIPTION OF TEACHING EXPERIENCE OR EDUCATIONAL RESEARCH}

The teaching methodology described herein has been implemented in a total of three academic years: 2017-2018, 2018-2019 and 2019-2020, throughout the 15 weeks that comprise the official teaching period of each of the two semesters corresponding to each one of the academic years (depending on the location in the semester, 1st or 2nd semester of each subject). The specific activities of this experience have been carried out within the first 8 weeks of each semester, since, being an innovative teaching experience, we believed that the most appropriate thing was to plan it in the first phase of each semester, in anticipation of the appearance of possible delays or technical or methodological inconveniences. The development of the research work has been included within the time schedules of the different teaching guides of the subjects involved, being consequently developed as a new learning process. The schedule described below (Table 2) shows the timing of the innovative experience in an indicative manner.

TABLE 2

SCHEDULE FOR IMPLEMENTATION OF THE EXPERIENCE: THE SAME WORKING PROTOCOL HAS BEEN APPLIED FOR ALL THE SUBJECTS INVOLVED

\begin{tabular}{|c|c|c|c|c|c|}
\hline Phase & Phase 1 & Phase 2 & Phase 3 & Phase 4 & \\
\hline $\begin{array}{c}\text { Weeks } \\
\text { semester }\end{array}$ & $0^{(1)}$ & $1-4$ & $5-6$ & 7 & $8-15$ \\
\hline Activity & $\begin{array}{l}\text {-Programming } \\
\text { the experience. } \\
\text { - Elaboration of } \\
\text { didactic material. }\end{array}$ & $\begin{array}{l}\text { - Description } \\
\text { of academic } \\
\text { activity. } \\
\text { - Access to } \\
\text { teaching } \\
\text { material. }\end{array}$ & $\begin{array}{l}\text { - Autonomous } \\
\text { student work. }\end{array}$ & $\begin{array}{l}\text { - Classroom } \\
\text { work. } \\
\text { - Shared } \\
\text { assessment. }\end{array}$ & $\begin{array}{l}\text { - Evaluation of } \\
\text { the experience. } \\
\text { - Generation of } \\
\text { reports and } \\
\text { valuation data. }\end{array}$ \\
\hline
\end{tabular}

(1) Preliminary work period, preceding the beginning of the 15-week teaching period of each semester. 


\section{TEACHING/RESEARCH METHODOLOGY}

A multi-stage process has been designed based on the application of the flipped classroom teaching method in foreign language teaching subjects, including the following significant methodological aspects:

The teaching team participating in this project works in 4 clearly defined phases (see conceptual design of the project, Figure 1, and Table 2). Thus, initially in (Phase 1), the experience is programmed, including a specific work schedule for each subject, and the didactic material is developed (monographs, tutorials, presentations, exercises, etc.) that will later be made available to the students. At this point, the different skills and objectives for their acquisition by the students are determined.

Subsequently, in (Phase 2), once the corresponding teaching period (semester) has started, the Moodle virtual platform is used to provide the students with the previously prepared material and the academic activity is displayed, providing the corresponding timetable for the didactic unit that is the object of the project in each subject.

At this point (Phase 3) the students begin their autonomous work with the purpose (from an eminently practical point of view) of generating doubts and questions about the material provided and the acquisition of specific skills of each unit in each case. At the same time, the teacher monitors the students' access to the virtual platform and the downloads of the teaching material, promoting, if necessary, the students' interest and motivation, and working according to a schedule for the acquisition of skills, closely related to the previously designed teaching material.

Finally, classroom work begins, mainly through a proactive teaching methodology (Phase 4). Based on the doubts generated by the students themselves, or on the results of the different self-evaluation questionnaires worked by them autonomously, different collaborative activities will be carried out, individually or in groups, in order to promote active learning.

\section{FIGURE 1}

\section{CONCEPTUAL DESIGN OF THE PROJECT}

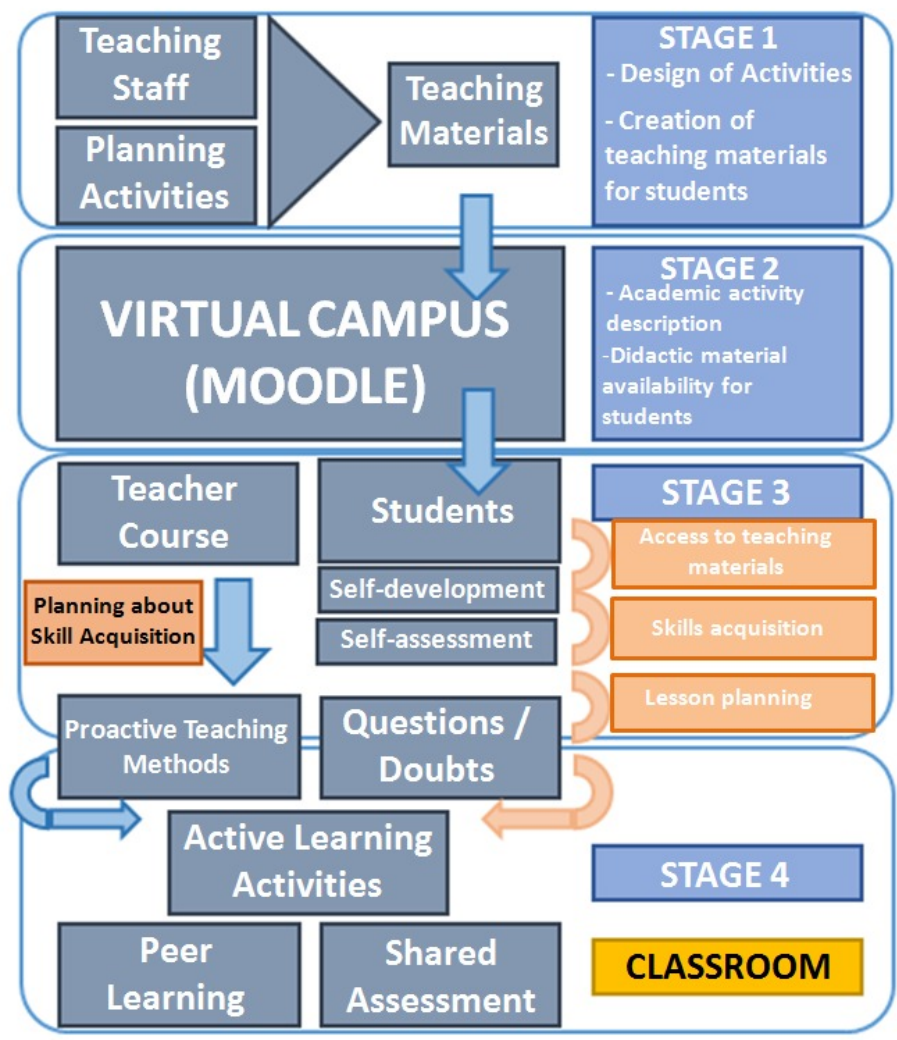


The activity evaluation has been carried out through evaluation questionnaires and a shared evaluation protocol between the different working groups that evaluate each other in a collaborative manner.

\section{RESULTS OBTAINED}

For the general evaluation of the educational research implemented, an evaluation questionnaire was designed (see Appendix 1), which contained a total of 17 questions related to the knowledge of participation in the innovative experience (questions 1,2 and 7), questions regarding the teaching methodology to be used (questions 3, 4, 5 and 6), and specific questions concerning knowledge and specific skills of the subjects in question (questions 8-17). Questionnaires were completed at the end of Phase 2 (INITIAL questionnaire, Figure 2) and at the end of the experience (FINAL questionnaire, Figure 3) with the general purpose of comparing the results and drawing conclusions regarding the innovative work developed.

\section{Graphical Expression and Analysis of Survey Results}

The initial questionnaire (see Figure 2) shows a significantly low score for question 1, in relation to knowledge of participation in an educational research project (for the students expressed as a Teaching Innovation Project, terminology with which they are more familiar) in the current course. Regarding the question of whether they have received enough information about the new methodologies that the teacher was going to carry out during the development of the innovative experience, the score is significantly adequate (3.59). Also positive is the acceptance of the innovations that the teacher has introduced in each of the subjects (question 7, score 4.00). The resulting average value corresponding to the questions concerning the methodology to be implemented (questions 3-6 of the questionnaire) has been very satisfactory in this initial questionnaire (3.70).

The average score for questions 8-17, regarding the specific knowledge and skills to be acquired in the subjects, is 3.06 in this initial questionnaire. It will be a special observation point because it will represent the positive evaluation of the experience in terms of learning and acquisition of skills at the end of the experience.

\section{FIGURE 2 \\ INITIAL QUESTIONNAIRE RESULTS}

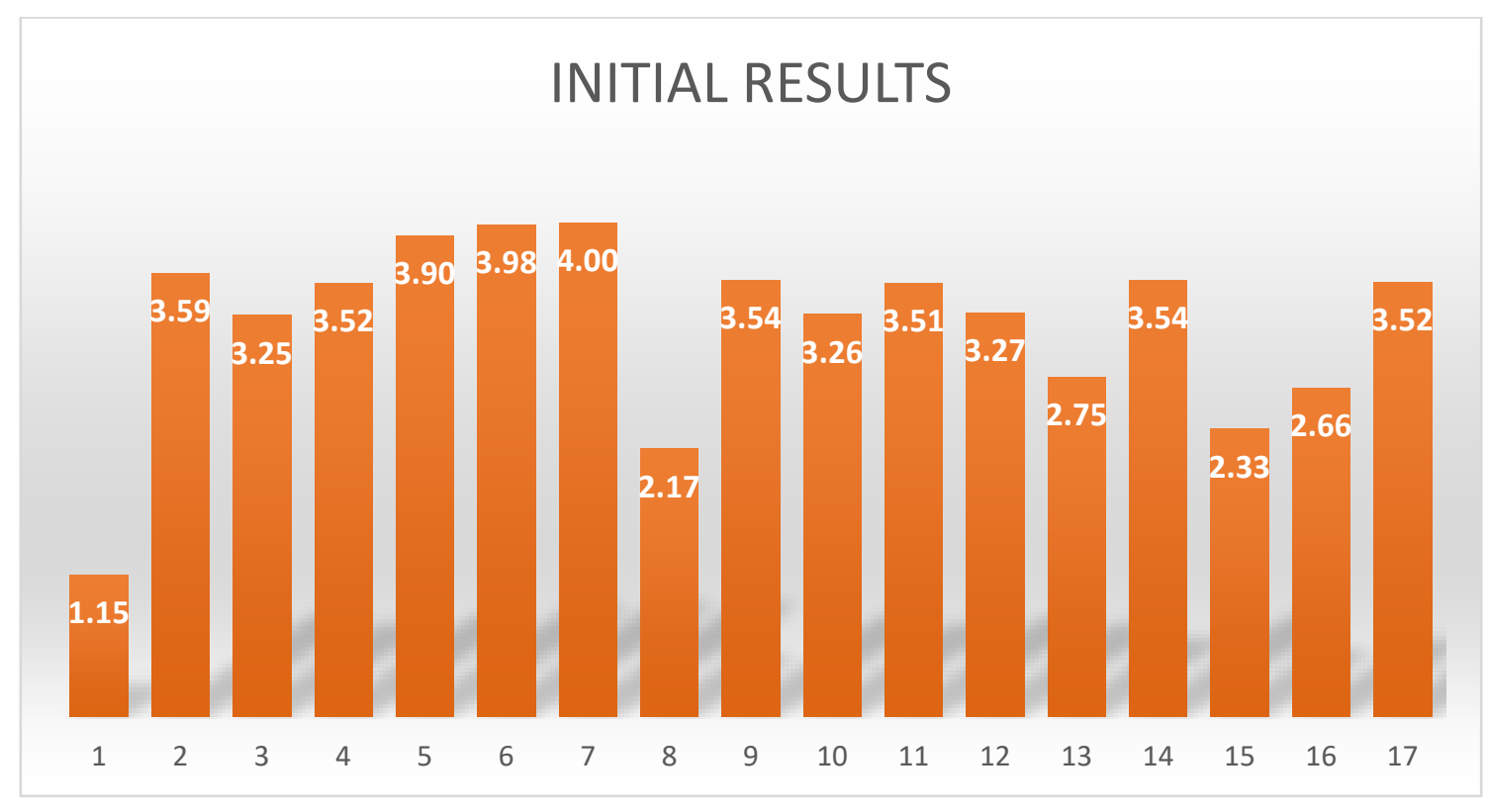


FIGURE 3

FINAL QUESTIONNAIRE RESULTS

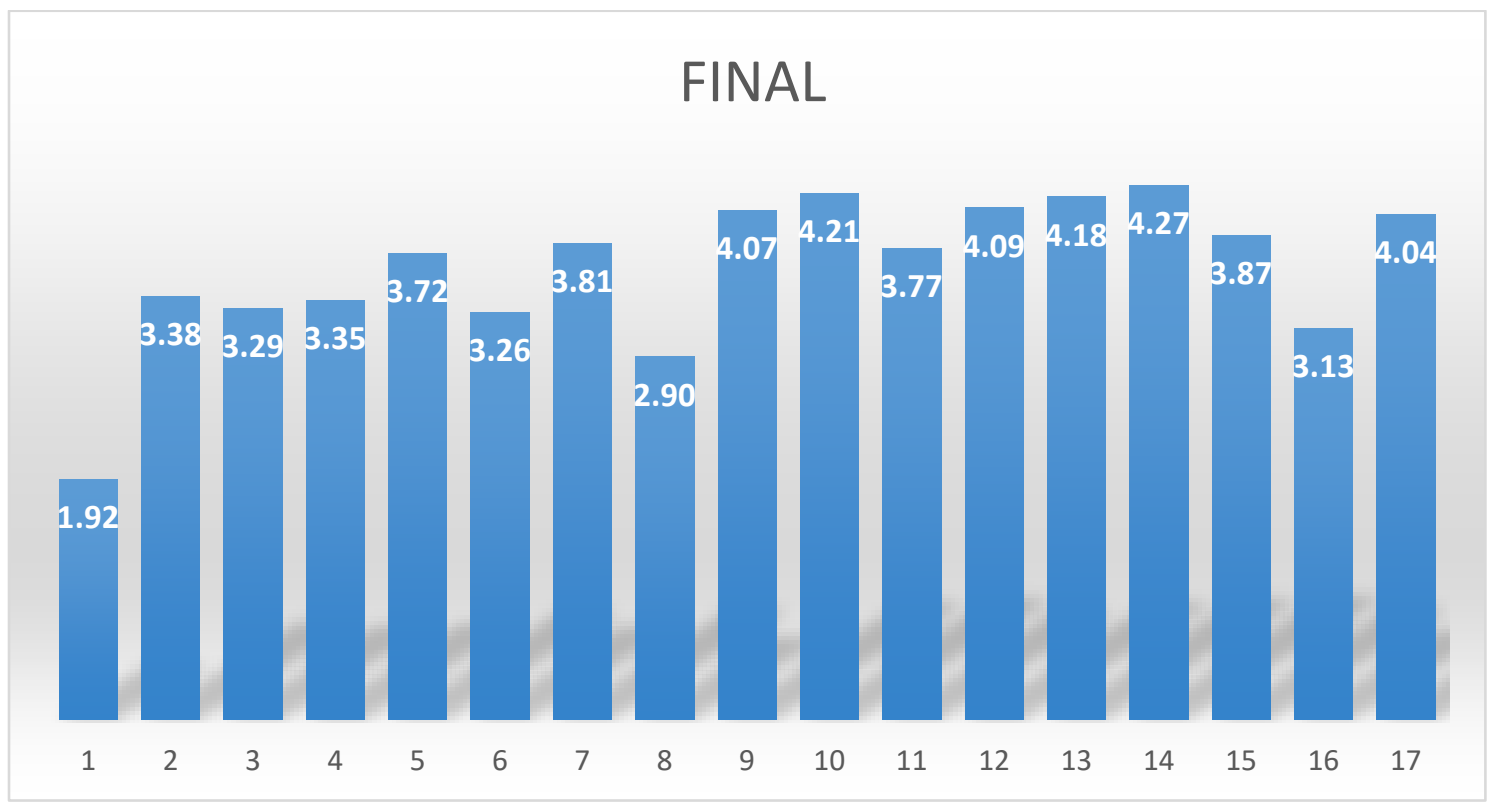

In the final questionnaire (see Figure 3) there is an increase, although not very significant, in the evaluation regarding question 1; nevertheless, some uncertainty is still detected in the students concerning their willingness to participate in an educational research project. The average evaluation of questions 817 , related to the specific knowledge and skills to be acquired in the subjects is 3.85 in the final questionnaire, which indicates that, according to the students' own opinions, there has been an improvement in the learning of specific knowledge of organic chemistry throughout the experience, or at least that the students as a whole feel more capable of expressing and defending knowledge of this branch of knowledge.

FIGURE 4

COMPARATIVE GRAPH OF THE RESULTS OF BOTH QUESTIONNAIRES.

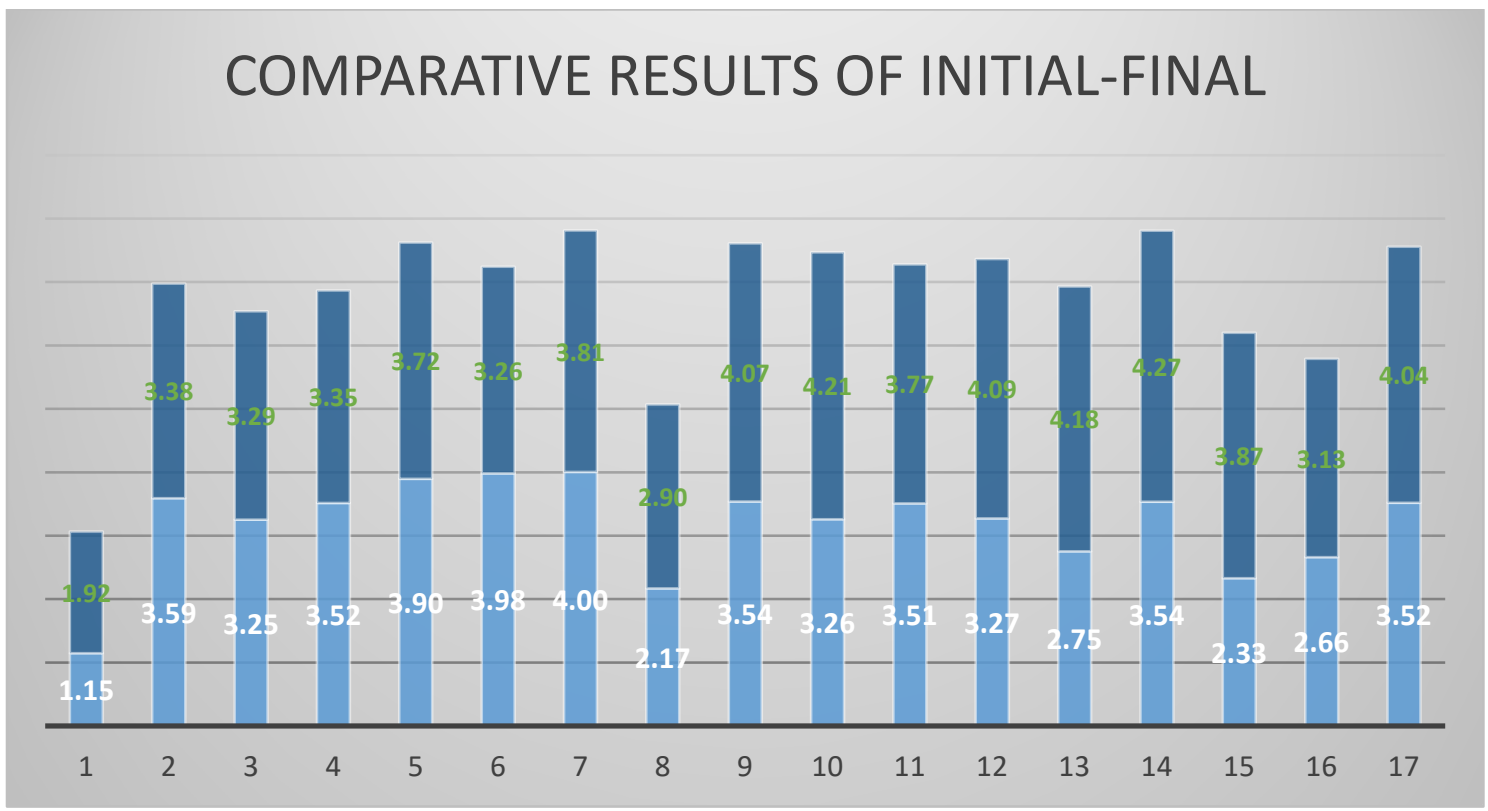


In the comparative of both questionnaires (Figure 4), it can be seen that for the block of questions 1-8, related to the knowledge of participation in the innovative experience and the teaching methodology to be used, as we said before, the score is slightly lower. This suggests that while the experience has been successful in terms of execution, implementation, as well as learning outcomes, students are relatively conservative and reluctant to participate in innovative experiences. This is what can be concluded at least if we consider that the students perceive that the teaching-learning model proposed in the experience places more responsibility on them to independently generate knowledge.

The particular questions related to specific knowledge and skills of the concerned subjects (questions 8-17) certainly show an increase in terms of their assessment in all cases, which reinforces what was expressed above regarding the success of the acquisition of skills and knowledge.

\section{CONCLUSIONS}

The implementation of this experience has been globally satisfactory. In general, the students have faced the acquisition of skills and competences in organic chemistry using English as a language, without this being a major difficulty, and focusing their efforts on knowledge acquisition. In chemistry-related skills, this type of teaching-learning protocol could be useful in advanced laboratory teaching, where students would have to design their own work and experimentation protocol to be developed under the teacher's guidance.

\section{ACKNOWLEDGEMENT}

Translated \& edited by American Publishing Services (https://americanpublishingservices.com/).

\section{REFERENCES}

Angelo, T. (1990). Learning in the classroom (phase I). A report from the Lawrence Hall of Science, Berkeley, CA. USA: University of California.

Bergmann, J., \& Sams, A. (2012). Flip your Classroom. United States of America: International Society for Technology in Education.

Escalera, G. (2008, September). La importancia del ciclo docente en la Universidad Española ante el Espacio Europeo de la Educación Superior. Revista Electrónica Sobre la Enseñanza de la Economía Pública, 4.

Isaza-Restrepo, A. (2005, June). Clases magistrales versus actividades participativas en el pregrado de medicina: De la teoría a la evidencia. Revista de Estudios Sociales, 20.

Jiménez Muñoz, A.J. (2013). Auge y caída de la clase al revés: ¿Lecciones aprendidas? Retrieved from https://www.academia.edu/7420281/Auge_y_ca\%C3\%ADda_de_la_clase_al_rev\%C3\%A9s_lecc iones_aprendidas ?auto=download

Jordan Lluch, C., Pérez Peñalver, M.J., \& Sanabria Codesal, E. (2014). Experiencias docentes. Investigación del impacto en un aula de matemáticas al utilizar flip education. Revista Pensamiento Matemático, IV, 09-022.

Sánchez, J. (2013, July-December). Sinergia educativa: Adaptación de una Clase Magistral en un. Instituto Tecnológico. Conciencia Tecnológica, 46.

Sosa-Pérez, O.A. (2014). El método colaborativo como una alternativa en el trabajo experimental de Química Orgánica. Educación Química, 25, 464-469.

Sousa, D.A. (1995). How the Brain Learns. Reston, VA: The National Association of Secondary School Principals. 


\section{APPENDIX 1: QUESTIONNAIRE}

Subject: Teacher:

The following questionnaire was designed to find out your perception of the teacher's use of new methods, forms, etc., during the development of his/her classes.

The information you provide will be processed anonymously and confidentially, and will be used only to achieve the research objectives.

Instructions: Answer the questions honestly keeping in mind that you have to indicate your degree of agreement $(1,2,3,4,5)$ with the following statements. 1 would be equivalent to "strongly disagree / No, not at all" and 5 to "strongly agree / Yes, of course". In case of not having information to answer, indicate ns/nc (don't know, no reply).

General data

\begin{tabular}{|c|c|c|}
\hline Gender: & Male & Female \\
\hline Age: & Years & \\
\hline
\end{tabular}

\begin{tabular}{|c|c|c|c|c|c|c|c|}
\hline & & 1 & 2 & 3 & 4 & 5 & $\mathrm{Ns} / \mathrm{nc}$ \\
\hline 1 & $\begin{array}{l}\text { I have known if the teacher has any Teaching Innovation Project } \\
\text { that he/she implements in this subject during its course. }\end{array}$ & & & & & & \\
\hline 2 & $\begin{array}{l}\text { During the course of the subject I will have enough information } \\
\text { regarding the new methodologies that the teacher is going to } \\
\text { carry out during the development of the subject. }\end{array}$ & & & & & & \\
\hline 3 & $\begin{array}{l}\text { My training needs as a student will be better met thanks to the } \\
\text { new methods used by this teacher. }\end{array}$ & & & & & & \\
\hline 4 & $\begin{array}{l}\text { Thanks to the innovative nature of the work model proposed by } \\
\text { the teacher, interaction with him/her can be improved. }\end{array}$ & & & & & & \\
\hline 5 & $\begin{array}{l}\text { The activities proposed by the teacher can contribute to make it } \\
\text { possible to learn better the theoretical and practical aspects of } \\
\text { the subject. }\end{array}$ & & & & & & \\
\hline 6 & $\begin{array}{l}\text { I think that the tutorial action by the teacher, understood as } \\
\text { accompaniment of the students, will be adequate as a } \\
\text { complementary way of training for the development of the } \\
\text { proposed activities. }\end{array}$ & & & & & & \\
\hline 7 & $\begin{array}{l}\text { I gladly accept the innovations that the teacher has introduced } \\
\text { in the subject. }\end{array}$ & & & & & & \\
\hline 8 & $\begin{array}{l}\text { Would you know how to develop by yourself a protocol to do a } \\
\text { thin layer chromatography? }\end{array}$ & & & & & & \\
\hline 9 & $\begin{array}{l}\text { Do you know the experimental development of a } \\
\text { recrystallization process? }\end{array}$ & & & & & & \\
\hline 10 & $\begin{array}{l}\text { Would you know how to explain to a partner the experimental } \\
\text { development of a liquid-liquid extraction? }\end{array}$ & & & & & & \\
\hline 11 & $\begin{array}{l}\text { Can you currently identify the corresponding waste canister } \\
\text { where to dispose of each of the substances used in the practices? }\end{array}$ & & & & & & \\
\hline 12 & $\begin{array}{l}\text { Would you know how to operate a rotary evaporator on your } \\
\text { own? }\end{array}$ & & & & & & \\
\hline
\end{tabular}




\begin{tabular}{|l|l|l|l|l|l|l|}
\hline 13 & $\begin{array}{l}\text { Do you see yourself qualified to set up a simple distillation } \\
\text { system? }\end{array}$ & & & & \\
\hline 14 & Do you know what anhydrous sodium sulfate is used for? & & & & & \\
\hline 15 & $\begin{array}{l}\text { Would you know what pumice stone is used for in a reflow } \\
\text { heating when a magnetic stirrer is not used? }\end{array}$ & & & & \\
\hline 16 & $\begin{array}{l}\text { Could you develop the reaction mechanism of a reduction with } \\
\text { NaBH }\end{array}$ & & & & \\
\hline 17 & $\begin{array}{l}\text { Would you know what we place solids in a desiccator for at the } \\
\text { end of practice? }\end{array}$ & & & & \\
\hline
\end{tabular}

Remarks:

Thank you very much for your cooperation 